\title{
Death by a thousand cuts: an ever increasing list of caspase substrates
}

\author{
Christopher Stroh ${ }^{1}$ and Klaus Schulze-Osthoff ${ }^{1,2}$ \\ ${ }^{1}$ Department of Internal Medicine I, Medical Clinics, University of Tübingen, \\ Germany \\ 2 corresponding author: Klaus Schulze-Osthoff, Department of Internal \\ Medicine I, Medical Clinics, Eberhard-Karls-University, Otfried-Müller-Str. 10, \\ D-72076 Tübingen, Germany. \\ Tel. +49-7071-29 84113; fax +49-7071-29 5865; \\ e-mail: schulze-osthoff@uni-tuebingen.de
}

At present, mammalian caspases comprise a group of at least 13 protease members which either generate mature pro-inflammatory cytokines or promote apoptosis (Cohen, 1997; Nicholson and Thornberry, 1997; Van de Craen et al, 1997; Humke et al, 1998; Schulze-Osthoff et al, 1998). Based on phylogenetic analysis and positional scanning studies of their peptide substrates, caspases can be divided into three subfamilies: The ICE-like protease family includes caspase-1, - $4,-5$ and -13 as well as murine caspase- 11 and -12 , for which no human equivalents have yet been identified. The Ced-3 subfamily includes caspase-3, -6, -7, $-8,-9$ and -10 , whereas the third subfamily consists of only one member, caspase-2. Within each subfamily, the peptide sequence preferences in the substrates are remarkably similar or even identical. This demonstrates that, at least in some cases, different caspases can cleave the same substrates, suggesting some degree of functional redundancy within the caspase family.

Central to the understanding of the molecular mechanism of cell death is the identification of caspase targets and the elucidation of the consequences of proteolytic cleavage. Thus far, more than 60 proteins have been found to be cleaved by caspases, and new substrates are continuously being identified (Table 1). Given the great number of different caspases, the list of substrates is still relatively small. For most proteins, the consequences of cleavage are poorly understood. In a few cases, however, proteolysis of certain components can be linked to discrete morphological changes of cell death.

Which requirements should an apoptosis-relevant caspase substrate meet? Because apoptosis is an ordered sequence of rather stereotypical alterations in every cell type, one would predict that caspase substrates should be ubiquitously expressed and evolutionary conserved, at least in their aspartate cleavage site. The known substrates of caspases can be loosely categorized into a few functional groups including proteins involved in scaffolding of the cytoplasm and cell nucleus, signal transduction and transcription-regulatory proteins, cell-cycle controlling components and proteins involved in DNA replication and repair. In addition, activation of members of the first subfamily of caspases, caspase- 1 and presumably caspase- 4 and -5 , results in the processing of cytokine precursors, which are presumably not directly involved in cell death.

While some substrates are functionally inactivated upon caspase-mediated cleavage, other proteins and enzymes can be activated, mostly by cleavage of an inhibitory or regulatory domain within the caspase target. In most cases the physiological consequence of this gain-of-function cleavage for apoptosis remains unclear. Caspasemediated cleavage should result in different net effects: (i) a halt of cell cycle progression, (ii) disabling of repair mechanisms, (iii) disassembly of molecular structures, (iv) cell detachment, and (v) tagging of the apoptotic cell for engulfment by phagocytes.

A number of structural proteins in the cell nucleus and cytoplasm have been identified to be cleaved by caspases, such as actin, fodrin, catenins, keratins, Gas2 and lamins (for references see Cohen, 1997; Nicholson and Thornberry, 1997; Porter et al, 1997; Tan and Wang, 1998; Cryns and Yuan, 1998). Degradation of lamin B which is predominantly mediated by caspase- 6 may lead to the disassembly of the nuclear envelope and the final collapse of the cell nucleus (Rao et al, 1996). In contrast, cleavage of gelsolin, a cytoplasmic actin-severing protein, may contribute to membrane blebbing and other morphological features of the apoptotic phenotype. Gelsolin is cleaved by caspase-3 to generate a constitutively active fragment that can depolymerize F-actin (Kothakota et al, 1997). Interestingly, gelsolin-deficient cells show a strong delay in membrane blebbing when exposed to apoptotic stimuli. It has been also reported that actin can be directly cleaved by caspases in pheochromocytoma and ovarian carcinoma cells (Kayalar et al, 1996; Chen et al, 1996), whereas in many other cell types no cleavage could be detected (Song et al, 1997). Thus, it is possible that certain protein cleavages may be cell typespecific which may also due to variations in the expression of individual caspases in different cell types. Activation of caspases may be not only required for destruction of the cell's architecture, but also necessary for the detachment and clearance of an apoptotic cell from the embedding tissue. Indeed, some caspase substrates participate in cell adhesion, such as $\beta$-catenin, plakoglobin and focal adhesion kinase (Brancolini et al, 1997; 1998; Herren et al, 1998; Crouch et al, 1996; Levkau et al, 1998a).

A strikingly large number of caspase targets are involved in cell cycle regulation and DNA repair mechanisms. One of the first death substrates found to be cleaved by caspases was poly(ADP-ribose)polymerase (PARP), which catalyzes the transfer of ADP-ribose polymers to nuclear proteins (Tewari et al, 1995). As DNA strand breaks activate the enzyme, PARP has been proposed to trigger DNA damageinduced apoptosis by depleting NAD stores. On the other hand, due to its role in DNA repair, cleavage of PARP may 
Table 1 Caspase substrates

Cytoskeletal and structural proteins

- Fodrin

- $\beta$-Catenin

- Plakoglobin ${ }^{1,2}$

- Actin

- Gelsolin

- Keratin-18,-19

- Gas2

- Lamins

Cell cycle and replication

- Topolsomerase-I

- MCM3 nuclear replication factor $^{3}$

- DNA replication complex C (DSEB/RFC140)

- MDM2/HDM2

- NuMA

- Retinoblastoma protein (Rb)

- p21 (Cip1/Waf1)

- p27 (Kip1)

- Wee $1^{5}$

- $\mathrm{Cdc} 27^{5}$

- Cyclin A

Transcription and translation

- Sterol-regulatory elementbinding proteins (SREBPs)

- STAT1 ${ }^{5}$

- NF- $\kappa$ B (p50, p65) ${ }^{7}$

- $I_{\kappa} \mathrm{B}-\alpha$

- Sp1

- U1-70 kD sRNP

- Heteronuclear ribonuclear proteins (hnRNPs C1/2)

DNA cleavage and repair

- Poly (ADP-ribose) polymerase (PARP)

- DNA-dependent protein kinase (DNA-PK)

- Inhibitor of caspaseactivated DNase (ICAD, DFF)
Cortical cytokeleton

Cell adhesion

Cell adhesion

Cytoskeleton

Actin-severing protein

Intermediate filaments

Microfilament organization

Nuclear envelope

DNA replication

DNA replication

DNA replication

Inhibitor of p53

Nuclear mitosis apparatus protein

Assembly of the repressor complex

Cdk2 inhibitor

Cdk inhibitor

Kinase, Cdc2 inhibitor

Anaphase-promoting complex

Mitosis

\section{Cholesterol metabolism}

Signal transduction of cytokines

Cytokine and anti-apoptotic genes

Inhibitor of NF- $k \mathrm{~B}$

Transcription factor

Pre-mRNA splicing

Pre-mRNA splicing

DNA repair

DNA repair

DNA cleavage
Protein kinases in signal transduction

- Protein kinase $\mathrm{C} \delta$

- Protein kinase $\mathrm{C} \theta$

- PKC-related kinase-2 (PRK2)

- MEKK-1

- p21-activated kinase (PAK2, hPAK65)

- PITSLRE kinases

- Focal adhesion kinase

- MST/krs ${ }^{8,9}$

- Calmodulin-dependent kinase IV $^{10}$

Other signal transducers

- Protein phosphatase 2A (PP2A) ${ }^{11}$

- D4-GDP dissociation inhibitor (D4-GDI)

- Ras GAP ${ }^{12,13}$

- p28 Bap31

- cytosolic PLA 2

Cytokine precursors

- Pro-interleukin-1 $\beta$

- Pro-interleukin-16 $6^{14}$

- Pro-interleukin-18 (IFN- $\gamma$-inducing factor)

transduction

Signal transduction

Signal transduction

MAP kinase pathway

MAP kinase pathway

Cell cycle regulation

Cell adhesion

STE20-related kinase

Signal transduction

Signal transduction

Inhibitor of small GTPases, Rho pathway

Ras GTPase activating protein

$\mathrm{Bcl}-2$ adaptor of the endoplasmic reticulum

Phospholipid metabolism

Immune regulation Immune regulation Immune regulation

Others

- Pro-caspases

- Rabaptin-5

- Calpastatin ${ }^{15,16}$

- Nedd4 ${ }^{17}$

- $\mathrm{Bcl}-2$

- $\mathrm{Bcl}-\mathrm{x}_{\mathrm{L}}$

- $\mathrm{Bid}^{18,19}$

- hsp90 20

- APC protein ${ }^{21}$

- Huntingtin

- Atrophin-122

- Ataxin- $3^{22}$

- DRPLA-protein ${ }^{23}$

- Presenilins
Endosome fusion

Ubiquitin protein ligase

Apoptosis inhibitor

Apoptosis inhibitor

Apoptosis activator

Heat-shock protein

Adenomatous polyposis coli protein

Involved in Huntington's disease Involved in neurodegeneration Involved in neurodegeneration Involved in neurodegeneration Involved in Alzheimer's disease

For a partial list of references the reader is referred to Cohen 1997; Nicholson and Thornberry, 1997; Porter et al, 1997; Tan and Wang, 1998; Cryns and Yuan ,1998. Non-cited and very recently identified caspase substrates are published in ${ }^{1}$ Herren et al, 1998; ${ }^{2}$ Brancolini et al, 1998; ${ }^{3}$ Schwab et al, $1998 ;{ }^{4}$ Levkau et al, $1998 \mathrm{~b}$; ${ }^{5}$ Zhou et al, 1998; King and Goodbourn, 1998; ${ }^{7}$ Ravi et al, 1998; ${ }^{8}$ Graves et al, 1998; ${ }^{9}$ Lee et al, 1998; ${ }^{10}$ McGinnis et al, 1998; ${ }^{11}$ Santoro et al, $1998 ;{ }^{2}$ Widmann et al, 1998; ${ }^{13}$ Wen et al, 1998; ${ }^{14}$ Zhang et al, 1998; ${ }^{15}$ Porn-Ares et al, 1998; ${ }^{16}$ Wang et al, 1998; ${ }^{17}$ Harvey et al, 1998; ${ }^{18}$ Luo et al, 1998; ${ }^{19} \mathrm{Li}$ et al, $1998 ;{ }^{20} \mathrm{Prasad}$ et al, 1998; ${ }^{21}$ Browne et al, 1998; ${ }^{22}$ Wellington et al, 1998. ${ }^{23}$ DRPLA,dentarorubral pallidoluysian atrophy

compromise most of its DNA repair activity, and thus may contribute to the demise of the cell. However, PARP $^{-1}-$ mice neither reveal a phenotype which would indicate a crucial role in apoptosis nor is the sensitivity towards CD95and TNF-R1-mediated apoptosis affected (Wang et al, 1997). Thus, cleavage of PARP may be a characteristic event or a bystander effect, but is presumably dispensable for most apoptotic pathways.

Retinoblastoma protein (RB) and the mouse double minute-2 protein (MDM2) are other examples of caspase substrates involved in repair mechanisms and cell cycle regulation (Jänicke et al, 1996; Erhardt et al, 1997). MDM2 normally retains p53 in the cytoplasm, and cleavage may allow p53 entry into the nucleus to induce cell cycle arrest or apoptosis. However, since apoptosis also occurs in enucleated cells, cleavage of nuclear proteins may be not essential for all apoptotic processes. It has been furthermore reported that cyclin $A$ is cleaved during apoptosis of Xenopus oocytes after treatment with hydroxyurea or cycloheximide (Stack and Newport, 1997). However, the caspase cleavage site of cyclin A is not conserved in mammalian cells, and the protein is not cleaved in a variety of apoptotic systems. Thus, one should not generalize a reported caspase substrate for all species. 
An increasing number of recently identified caspase substrates are protein kinases or other proteins involved in signal transduction. In many cases, caspase cleavage results in the removal of a regulatory protein domain generating a constitutively active kinase. For instance, proteolytic activation of the p21-activated kinase PAK2 has been reported during CD95 and TNF-mediated apoptosis (Rudel and Buckoch, 1997). As PAK2 is able to trigger stress-activated kinases of the JNK/SAPK pathway, this may provide a link between caspases and JNK/SAPK activation during apoptosis signaling. Interestingly, blocking the activity of PAK2 by a dominant-negative mutant led to the inhibition of formation of apoptotic bodies, whereas nuclear apoptosis and phosphatidylserine externalization remained unaffected. Therefore, the cleavage of PAK2 is an example of how different features of apoptosis might be discriminated at the level of caspase targets.

The activation of certain proteins by caspases is mediated by a rather limited and specific endoproteolytic cleavage, which is a general feature of caspase activity. Among other enzymes activated by caspases are cytosolic phospholipase $A_{2}$, protein kinases such as MEKK-1, MST, the PKC isoforms delta and theta, PKC-related kinase-2, and transcription factors such as the sterol-regulatory element binding protein (SREBP)-1 and -2 . It still remains to be established, whether caspase-mediated activation of one of these molecules is involved in transduction of the apoptotic signal. It has been also observed that antiapoptotic proteins of the Bcl-2 family are cleaved by caspases (Cheng et al, 1997; Clem et al, 1998). This cleavage results in their conversion to pro-apoptotic proteins which may similar act to Bax and thereby amplify an apoptotic signal. Similarly, it has been observed that during death receptor-mediated apoptosis caspase- 8 can cleave the $\mathrm{Bcl}-2$ member Bid into an active C-terminal fragment that induces the pro-apoptotic release of cytochrome c from mitochondria (Luo et al, 1998; Li et al, 1998). A caspase-mediated activation of cellular functions has been recently provided by the identification of a novel murine endonuclease, designated CAD for caspaseactivated DNase (Enari et al, 1998). CAD is sequestered in the cytosol as a latent form by binding to the inhibitory subunit, called ICAD, whose human homologue has been previously identified as DNA fragmentation factor (DFF) (Liu et al, 1997). Upon induction of apoptosis, ICAD/DFF is cleaved by caspase-3, which allows the DNase to translocate to the nucleus and to degrade DNA. Interestingly, overexpression of ICAD blocks chromatin changes of apoptosis but does not abrogate other morphological alterations.

The cleavage of some substrates can be directly linked to the pathogenesis of certain diseases. Huntington's disease, a genetically determined neurodegenerative disease, results from the expansion of CAG triplets at the 5 -primed end of the gene encoding huntingtin, a protein with a long polyglutamine stretch. Huntingtin is cleaved by caspase- 3 and results in an N-terminal fragment which is directly cytotoxic for neurons (Goldberg et al, 1996). Huntington's disease manifests only when huntingtin exceeds 35 glutamine residues. Because the rate of caspase cleavage of huntingtin correlates with the length the polyglutamine stretch, accumulation of the fragment may cause a vicious cycle. It is interesting to note that, although mutated huntingtin is ubiquitously expressed, the genetic lesion is associated with apoptosis only in certain brain regions. A pathogenic role of caspase cleavage has been also implicated in other neurodegenerative disorders. Similar to huntingtin, the polyglutamine tract proteins atrophin-1, ataxin-3 and DRPLA-protein are caspase substrates (Wellington et al, 1998; Miyashita et al, 1997). The cytotoxic properties of their cleavage products illustrate that specific caspase substrates may be not only involved in the destruction of the cell, but also fulfil an active role in the exacerbation of the apoptotic process.

Is there a single caspase substrate whose cleavage is critical or relatively more important for cell death? It should be pointed out that thus far none of the cleavage events has been shown to be absolutely required to kill cells. Although ectopic overexpression of non-cleavable mutants (for example of Rb, PAK-2 or MEKK-1) delays some forms of apoptosis or inhibits certain morphological features of cell death, in any case, final cell death could not be prevented. This is in contrast to the effect of pharmaceutical caspase inhibitors and may suggest that a critical death substrate might not have been identified yet. More likely, however, is that apoptosis requires 'a thousand cuts' (Martin and Green, 1995), each contributing to a part of the apoptotic phenotype. The cleavage of multiple substrates with key homeostatic and structural functions may then collectively culminate in the systematic and orderly disassembly of the apoptotic cell.

\section{References}

(Owing to space limitations, the authors apologize that many articles which significantly contributed to the elucidation of caspase substrates could not be cited.)

Brancolini C, Lazarevic D, Rodriguez J and Schneider C (1997) Dismantling cell-cell contacts during apoptosis is coupled to a caspase-dependent proteolytic cleavage of $\beta$-catenin. J. Cell Biol. 139: 759-771

Brancolini C, Sgorbissa A and Schneider C (1998) Proteolytic processing of the adherens junctions components $\beta$-catenin and $\gamma$-catenin/plakoglobin during apoptosis. Cell Death Differ., 5: 1042-1050

Browne SJ, MacFarlane M, Cohen GM and Paraskeva C (1998) The adenomatous polyposis coli protein and retinoblastoma protein are cleaved early in apoptosis and are potential substrates for caspases. Cell Death Differ. 5: 206-213

Chen Z, Naito M, Mashima T and Tsuruo T (1996) Activation of actin-cleavable interleukin-1 $\beta$-converting enzyme (ICE) family protease CPP-32 during chemotherapeutic agent-induced apoptosis in ovarian carcinoma cells. Cancer Res. 56: 5224-5229

Cheng EHY, Kirsch DG, Clem RJ, Ravi R, Kastan MB, Bedi A, Ueno K and Hardwick JM (1997) Conversion of Bcl-2 to a Bax-like effector by caspases. Science 278: 1966-1968

Clem RJ, Cheng HY, Karp CL, Kirsch DG, Uueno K, Takahashi A, Kastan MB, Griffin DE, Earnshaw WC, Veliuona MA and Hardwick JM (1998) Modulation of cell death by Bcl- $\mathrm{x}_{\mathrm{L}}$ through caspase interaction. Proc. Natl. Acad. Sci. USA 95: $554-559$

Cohen GM (1997) Caspases: the executioners of apoptosis. Biochem. J. 326: 1-16

Crouch DH, Fincham VJ and Frame MC (1996) Targeted proteolysis of focal adhesion kinase pp125 FAK during c-MYC-induced apoptosis is suppressed by integrin signalling. Oncogene 12: 2689-2696

Cryns V and Yuan J (1998) Proteases to die for. Genes Dev. 12: 1551 - 1570 
Enari M, Sakahiera H, Yokoyama H, Okawa K, Iwamatsu A and Nagata S (1998) A caspase-activated DNase that degrades DNA during apoptosis, and its inhibitor ICAD. Nature 391: 43-50

Erhardt P, Tomaselli KJ and Cooper GM (1997) Identification of the MDM2 oncoprotein as a substrate for CPP32-like apoptotic proteases. J. Biol. Chem. 272: $15049-15052$

Goldberg YP, Nicholson DW, Rasper DM, Kalchman MA, Koide HB, Graham RK, Bromm M, Kazemi-Esfarjani P, Thornberry NA, Vaillancourt JP and Hayden MR (1996) Cleavage of huntingtin by apopain, a proapoptotic cysteine protease, is modulated by the polyglutamine tract. Nature Genetics 13: 442-449

Graves JD, Gotoh Y, Draves KE, Ambrose D, Han DKM, Wright M, Chernoff J, Clark EA and Krebs EG (1998) Caspase-mediated activation and induction of apoptosis by the mammalian STE-like kinase Mst1. EMBO J. 17: 2224-2234

Harvey KF, Harvey NL, Michael JM, Parasivam G, Waterhouse N, Alnemri ES, Watters D and Kumar S (1998) Caspase-mediated cleavage of the ubiquitinprotein ligase Nedd4 during apoptosis. J. Biol. Chem. 273: 13524-13530

Herren B, Levkau B, Raines EW and Ross R (1998) Cleavage of $\beta$-catenin and plakoglobin and shedding of VE-cadherin during endothelial apoptosis: Evidence for a role of caspases and metalloproteases. Mol. Biol. Cell 9 : $1589-1601$

Humke EW, Ni J and Dixit VM (1998) ERICE, a novel FLICE-cleavable caspase. J. Biol. Chem. 273: 15702-15707

Jänicke RU, Walker PA, Lin XY and Porter AG (1996) Specific cleavage of the retinoblastoma protein by an ICE-like protease in apoptosis. EMBO J. 15:69696978

Kayalar C, Ord T, Testa MP, Zhong LT and Bredesen DE (1996) Cleavage of actin by interleukin $1 \beta$-converting enzyme to reverse DNase I inhibition. Proc. Natl. Acad. Sci. USA 93: 2234-2238

King P and Goodbourn S (1998) STAT1 is inactivated by a caspase. J. Biol. Chem. 273: $8699-8704$

Kothakota S, Azuma T, Reinhard C, Klippel A, Tang J, Chu K, McGarry TJ, Kirschner MW, Koths K, Kwiatkowski DJ and Williams LT (1997) Caspase-3-generated fragment of gelsolin: effector of morphological change in apoptosis. Science 278 : $294-298$

Lee KK, Murakawa M, Nishida E, Tsubuki S, Kawashima S, Sakamaki K and Yonehara S (1998) Proteolytic activation of MST/Krs, STE20-related protein kinase, by caspase during apoptosis. Oncogene 16: 3029-3037

Levkau B, Herren B, Koyama H, Ross R and Raines EW (1998a) Caspase-mediated cleavage of focal adhesion kinase pp125 (FAK) and disassembly of foca adhesions in human endothelial cell apoptosis. J. Exp. Med. 187: 579-586

Levkau B, Koyama H, Raines EW, Clurman BE, Herren B, Orth K, Roberts JM and R Ross (1998b) Cleavage of p21 (Cip1/Waf1) and p27 (Kip1) mediates apoptosis in endothelial cells through activation of Cdk2: role of a caspase cascade. Mol. Cell 1: $553-563$

Li H, Zhu H, Xu CJ and Yuan J (1998) Cleavage of BID by caspase 8 mediates the mitochondrial damage in the Fas pathway of apoptosis. Cell 94: 491-501

Liu X, Zou H, Slaughter C and Wang X (1997) DFF, a heterodimeric protein that functions downstream of caspase 3 to trigger DNA fragmentation during apoptosis. Cell 89: 175-184

Luo X, Budihardjo I, Zou H, Slaughter C and Wang X (1998) Bid, a Bcl2 interacting protein, mediates cytochrome $c$ release from mitochondria in response to activation of cell surface death receptors. Cell 94: 481-490

Martin SJ and Green DR (1995) Protease activation during apoptosis: death by a thousand cuts. Cell 82: $349-352$

McGinnis KM, Whitton MM, Gnegy ME and Wang KKW (1998) Calcium/calmodulindependent protein kinase IV is cleaved by caspase-3 and calpain in SH-SY5Y human neuroblastoma cells undergoing apoptosis. J. Biol Chem. 273: 1999320000

Miyashita T, Okamura-Oho Y, Mito Y, Nagafuchi S and Yamada M (1997) Dentatorubral pallidoluysian atrophy (DRPLA) protein is cleaved by caspase-3 during apoptosis. J. Biol. Chem. 272: 29238-29242

Nicholson DW and Thornberry NA (1997) Caspases: killer proteases. Trends Biochem. Sci. 22: 299-306
Pörn-Ares MI, Samali A and Orrenius A (1998) Cleavage of calpain inhibitor, calpastatin, during apoptosis. Cell Death Differ., 5: 1028-1033

Porter AG, Ng P and Jänicke RU (1997) Death substrates come alive. BioEssays 19: $501-507$

Prasad S, Soldatenkov VA, Srinivasarao G and Drischilo A (1998) Identificationof keratins 18,19 and heat-shock protein 90 as candidate substrates of proteolysis during ionizing radiation-induced apoptosis of estrogen-receptor negative tumour cells. Int J Oncol. 13: 757-764

Rao L, Perez D and WhiteE (1996) Lamin proteolysis facilitates nuclear events during apoptosis. J. Cell Biol. 135: 1441 - 1455

Ravi R, Bedi A, Fuchs EJ and Bedi A (1998) CD95 (Fas)-induced caspase-mediated proteolysis of NF- $\kappa$ B. Cancer Res. 58: 882-886

Rudel T and Bokoch GM (1997) Membrane and morphological changes in apoptotic cells regulated by caspase-mediated activation of PAK2. Science 276: $1571-$ 1574

Santoro MF, Annand RR, Robertson MM, Peng YW, Brady MJ, Mankovich JA, Hackett MC, Ghayur T, Walter G, Wong WW and Giegel DA (1998) Regulation of protein phosphatase $2 \mathrm{~A}$ activity by caspase-3 during apoptosis. J. Biol. Chem. 273: $13119-13128$

Schulze-Osthoff K, Ferrari D, Los M, Wesselborg S and Peter ME (1998) Apoptosis signaling by death receptors. Eur. J. Biochem. 254: 439-459

Schwab BL, Leist M, Knipper R and Nicotera P (1998) Selective proteolysis of the nuclear replication factor MCM3 in apoptosis. Exp. Cell Biol. 238: 415-421

Song Q, Wei T, Lees Miller S, Alnemri E, Watters D and Lavin MF (1997) Resistance of actin to cleavage during apoptosis. Proc. Natl. Acad. Sci. USA 94: 157-162

Stack JH and Newport JW (1997) Developmentally regulated activation of apoptosis early in Xenopus gastrulation results in cyclin A degradation during interphase of the cell cycle. Development 124: 3185-3195

Tan X and Wang JYJ (1998) The caspase-RB connection in cell death. Trends Cell Biol. 8: $116-120$

Tewari M, Quan LT, O'Rourke K, Desnoyers S, Zeng Z, Beidler DR, Poirier GG, Salvesen GS and Dixit VM (1995) Yama/CPP32 beta, a mammalian homolog of CED-3, is a CrmA-inhibitable protease that cleaves the death substrate poly(ADP-ribose) polymerase. Cell 81: 801-809.

Van de Craen M, Vandenabeele P, Declercq W, Van den Brande I, Van Loo G, Molemans F, Schotte P, Van Criekinge W, Beyaert R and Fiers W (1997) Characterization of seven murine caspase family members. FEBS Lett. 403: $61-69$

Wang ZQ, StingI L, Morrison C, Jantsch M, Los M, Schulze-Osthoff Kand Wagner EF (1997) PARP is important for genomic stability but dispensable in apoptosis. Genes Dev 11: 2347-2358.

Wang KKW, Posmantur R, Nadimpalli R, Nath R, Mohan P, Nixon RA, Talanian RV, Keegan M, Herzog L and Allen $\mathrm{H}$ (1998) Caspase-mediated fragmentation of calpain inhibitor protein calpastatin during apoptosis. Arch Biochem Biophys 356: $187-196$

Wellington CL, Ellerby LM, Hackam AS, Margolis RL, Trifiro MA, Singaraja R, McCutcheon K, Salvesen GS, Propp SS, Bromm M, Rowland KJ, Zhang T, Rasper D, Roy S, Thornberry N, Pinsky L, Kakizuda A, Ross CA, Nicholson DW, Bredesen DE and Hayden MR (1998) Caspase cleavage of gene products associated with triplet expansion disorders generates truncated fragments containing the polyglutamine tract. J. Biol. Chem. 273: 9158-9167

Wen L-P, Madani K, Martin GA and Rosen GD (1998) Proteolytic cleavage of Ras GTPase- activating protein during apoptosis. Cell Death Differ. 5: 729-234

Widmann C, Gibson S and Johnson GL (1998) Caspase-dependent cleavage of signaling proteins during apoptosis. A turn-off mechanism for anti-apoptotic signals. J. Biol. Chem. 273: 7141-7147

Zhang YJ, Center DM, Wu DMH, Cruikshank WW, Yuan JY, Andrews DW and Kornfeld $\mathrm{H}$ (1998) Processing and activation of pro-interleukin- 16 by caspase-3. J. Biol. Chem. 273: 1144-1149

Zhou BB, LiH, Yuan J, Kirschner MW (1998) Caspase-dependent activation of cyclindependent kinases during fas-induced apoptosis in Jurkat cells. Proc. Natl. Acad. USA 95: 6785-6790 